\title{
Biological effects of ion beam irradiation on perennial gentian and apple
}

\author{
Nobuhiro Sasaki 1,a , Aiko Watanabe ${ }^{1}$, Tomonori Asakawa², Makoto Sasaki², \\ Nobue Hoshi ${ }^{2}$, Zenbi Naito², Yoshiya Furusawa ${ }^{3}$, Takashi Shimokawa ${ }^{3}$, \\ Masahiro Nishihara ${ }^{1, *}$ \\ ${ }^{1}$ Iwate Biotechnology Research Center, 22-174-4 Narita, Kitakami, Iwate 024-0003, Japan; ${ }^{2}$ Iwate Agricultural Research \\ Center, 20-1 Narita, Kitakami, Iwate 024-0003, Japan; ${ }^{3}$ National Institute of Radiological Sciences, National Institutes of \\ Quantum and Radiological Science and Technology, 4-9-1 Anagawa, Inage-ku, Chiba-shi, Chiba 263-8555, Japan \\ *E-mail: mnishiha@ibrc.or.jp Tel: +81-197-68-2911Fax: +81-197-68-3881
}

Received November 30, 2017; accepted June 12, 2018 (Edited by T. Aoki)

\begin{abstract}
The development of new varieties of perennial plants generally requires lengthy and laborious procedures. In this study, we used ion beam irradiation mutagenesis in an attempt to accelerate the breeding process for perennial plants. We evaluated the biological effects of five ion beam sources (carbon, neon, argon, silicon, and iron) and neutron irradiation on Japanese gentian and apple. These treatments were applied at the National Institute of Radiological Sciences (NIRS) using the Heavy Ion Medical Accelerator in Chiba (HIMAC) and the Neutron-exposure Accelerator System for Biological Effect Experiments (NASBEE). Biological effects were observed in in vitro gentian plants after irradiation with ion beams at $<10 \mathrm{~Gy}$, whereas apple trees were less sensitive to ion beam irradiation. The growth of gentians in vitro was repressed by $3 \mathrm{~Gy}$ neutron irradiation, while that of grafted apple trees was not affected by $4 \mathrm{~Gy}$ neutron irradiation. During in vitro proliferation, seven pink-flowered lines were obtained from originally blue-flowered gentian after $\mathrm{C}$ and $\mathrm{Ne}$ ion beam irradiation treatments. Genomic and reverse transcription-PCR analyses of these lines suggested that the mutations occurred in the genomic region containing $\mathrm{F3}^{\prime} 5^{\prime} \mathrm{H}$ (encoding flavonoid $3^{\prime}, 5^{\prime}$-hydroxylase). These results provide useful information for the mutagenesis and breeding of gentian, apple, and other perennial plants.
\end{abstract}

Key words: apple, HIMAC, ion beam breeding, Japanese gentian, mutagenesis.

\section{Introduction}

It takes considerable skill, labor, and time to develop new crop varieties, and it is more labor- and timeconsuming to breed perennial crops than to breed annual ones. The long life cycle and various traits such as selfincompatibility, heterogeneity, and inbreeding depression can decrease the breeding efficiency of agricultural crops. Therefore, several breeding systems including theoretical and molecular breeding methods have been developed (Al-Khayri et al. 2015; Charlesworth 2006). Japanese cultivated gentians have been bred from two endemic species (Gentiana triflora and Gentiana scabra) as cut or potted flowers for more than 30 years in Iwate Prefecture. Apple breeding also occurs in Iwate prefecture, and five new cultivars have been developed so far. Both plant species are perennials with long life cycles (at least 2 years to reach flowering in gentian, and at least 3 years to reach flowering in apple). Therefore, the breeding of elite cultivars usually takes years. Japanese gentians show inbreeding depression and apple shows self-incompatibility. Thus, breeding strategies based on selection from self-pollinated plants that are used for major crops such as rice, wheat, soybean, and tomato are less suitable for apple and gentian. It is difficult to fix useful agronomical traits in only a few years in gentian and apple.

Recently, we summarized the current state of knowledge on the breeding and cultivation of Japanese gentians (Nishihara et al. 2018), and the history of apple cultivars and apple breeding in Japan has also been reviewed (Igarashi et al. 2016). Japanese gentian flowers are normally a vivid blue color, but some pinkor white-colored varieties have been developed from

Abbreviations: DFR, dihydroflavonol 4-reductase; $F 3^{\prime} 5^{\prime} H$, flavonoid 3' $5^{\prime}$-hydroxylase; HIMAC, Heavy Ion Medical Accelerator in Chiba; LET, linear energy transfer; NASBEE, Neutron-exposure Accelerator System for Biological Effect Experiments.

${ }^{a}$ Present address: Department of Food and Nutritional Sciences, Faculty of Food and Nutritional Sciences, 1-1-1 Izumino, Itakura-machi, Ora-gun, Gunma 374-0193, Japan

This article can be found at http://www.jspcmb.jp/

Published online August 2, 2018 
natural mutants. New flower colors would increase the marketability of Japanese gentian, but this is difficult to achieve because the pink and white flower colors are recessive traits. Previously, we showed that changes in gentian flower color were due to insertions of transposable elements or insertions/deletions in genes encoding flavonoid biosynthetic enzymes or transcription factors (Nakatsuka et al. 2005, 2006; Nishihara et al. 2011). We also developed DNA markers to distinguish pink- and white-flowered lines from blueflowered ones to promote efficient breeding (Kakizaki et al. 2009; Nakatsuka et al. 2012). More recently, we analyzed a double-flowered gentian mutant and developed a DNA marker to distinguish flower shape (Nakatsuka et al. 2015; Tasaki et al. 2016). Nevertheless, there is much less variation in Japanese gentian than in other major flowers such as rose, chrysanthemum, and carnation. One reason for the low level of variation is that there are limited natural mutations and genetic resources available for Japanese cultivated gentians. Artificial mutation is a promising approach to increase the genetic resources available for gentian breeding, but no mutagenesis methods have been established for this species so far.

It takes at least 3 years to harvest the first fruits after cross-pollination. Although the apple genome has been fully sequenced and molecular breeding methods such as marker-assisted selection have been developed for apple breeding (Igarashi et al. 2016; Velasco et al. 2010), the development of elite cultivars is still expensive in terms of time and labor. When elite cultivars are developed, further improvement is difficult and time-consuming. Mutation breeding is an alternative to cross-breeding, and it has been successfully applied to many vegetatively propagated crops (Jankowicz-Cieslak et al. 2017). For example, 'Fuji,' one of the most popular modern apple cultivars, has produced many bud varieties as a result of natural mutations. However, the mutation rate of apple is relatively low under natural cultivation conditions, and so efficient mutation techniques are required.

To obtain mutant lines of crops with high efficiency, several mutagenesis methods have been developed over the last 50 years. These methods include chemical mutagenesis using compounds such as sodium azide, ethylnitrosourea, and ethyl methanesulfonate, and physical mutagenesis using X-rays and gamma rays (ElNashar and Asrar 2016; Lee et al. 2003; Matsuo et al. 1958; Yamaguchi et al. 2009b). For more than a decade, several facilities to provide heavy ion beams have been available and heavy ion beam irradiation techniques have been used to create new varieties of several crops, including ornamental flowers such as dahlia, verbena, and carnation (Kazama et al. 2008; Okamura et al. 2003; Yamaguchi 2018). Heavy ion beams are ionized heavy particles of an atomic nucleus which are electrically accelerated to approximately $80 \%$ of light speed. Compared with X-rays and gamma rays, ion beams provide high energy to a target more densely and locally. Recently, a facility to provide neutron irradiation has become available (Suda et al. 2009). Neutron irradiation delivers accelerated non-charged particles, and their effects on biological targets are thought to differ from those of charged particles like ion beams.

Several studies have focused on the biological effects of ion beam irradiation on plant seeds. In some studies, shoots and hypocotyls were subjected to heavy ion beam irradiation to produce new lines of chrysanthemum, petunia, carnation, and cyclamen (Hase et al. 2010; Kondo et al. 2009; Okamura et al. 2003; Sugiyama et al. 2008; Yamaguchi et al. 2009b). The biological effects of ion beam irradiation depend on the LET value (Shikazono et al. 2002). Understanding the effects of the irradiation dose is very useful when applying this technique in plant breeding, because the mutation rate is greatly affected by the LET and the irradiation dose (Kazama et al. 2013, 2008).

In general, short-range heavy ion beams cannot be used to irradiate thick tissues including budwoods of trees, node cultures, and plantlets. This is because the LET is drastically transmuted in the Bragg peak region (Ryuto et al. 2008). The Heavy Ion Medical Accelerator in Chiba (HIMAC) is a piece of equipment designed for cancer radiation therapy. The high-energy ion beams accelerated by the HIMAC provide equal-LET irradiation in the long-distance plateau region, even when heavier ions such as argon (Ar) and iron ( $\mathrm{Fe}$ ) atoms are used. Twigs of trees or in vitro cultured plantlets up to ca. $10 \mathrm{~cm}$ size can be subjected to ion beam irradiation generated by the HIMAC, and then grafted onto rootstock or propagated in vitro, respectively. The plantlets obtained from cultivated shoots and new trees obtained from cuttings of mature trees start to flower and fruit much earlier than do seedlings. Therefore, using cultured shoots and twigs (cuttings) for ion beam irradiation experiments shortens the time to evaluate the mutation rates, compared with using seeds or cotyledon explants.

In this study, we used the HIMAC facility at the National Institute of Radiological Sciences (NIRS) to irradiate cultured Japanese gentians and apple twigs with several types of heavy ion beams (carbon, neon, Ar, silicon, and $\mathrm{Fe}$ ). We also used the neutron accelerator to examine the biological effects of neutron irradiation using the Neutron-exposure Accelerator System for Biological Effect Experiments (NASBEE) facility at the NIRS. We conducted the neutron irradiation experiments because few studies have evaluated the biological effects of neutron irradiation, and we thought the data would be useful for the further development of mutagenesis. We evaluated the biological effects 
of radiation to obtain information for the mutation breeding of these two crops. We obtained gentian lines with modified flower color by $\mathrm{Ne}$ and $\mathrm{C}$ ion beam irradiation, and determined the nature of the genetic mutation. This is the first report on the biological effects of ion beam and neutron irradiation on perennial gentian and apple plants.

\section{Materials and methods}

\section{Plant materials}

The Japanese gentian cultivars 'Aokorin' and 'Albireo' and the breeding line 'Bzc-1' were used in these irradiation experiments. These cultivars were maintained in vitro as described previously (Tasaki et al. 2016). Plantlets grown from segment nodes approximately 2 weeks after transfer were subjected to heavy ion beam irradiation treatments. To assess the biological effects, segment nodes were placed in Incu Tissue polycarbonate containers (SPL Life Sciences Co., Ltd., Gyeonggi-do, Korea; D $72 \times$ W $72 \times$ H100 mm) alongside a measurement scale, photographed, and the elongated shoot length was measured (summarized in Figure 1). Statistical analyses (Tukey-Kramer test) were conducted using the $\mathrm{R}$ statistical computing environment ( $\mathrm{R}$ x64 3.4.3).

Twigs of 'Oyume' apple trees (Malus $\times$ domestica) were collected from field-grown trees in February and stored at $4^{\circ} \mathrm{C}$. The twigs were cut into $10-\mathrm{cm}$ lengths and the cross sections were preserved in Callus mate ${ }^{\mathrm{TM}}$ (Fuji Yakuhin Kogyo, Tokyo). Each twig contained approximately three buds. The irradiated twigs were stored at $4^{\circ} \mathrm{C}$ until grafting in the spring.

\section{Heavy ion beam irradiation}

The ion beam irradiation experiments were performed at NIRS, using the HIMAC, as part of the "Research Project with Heavy Ions at NIRS-HIMAC". We used five kinds of ion beams, ${ }^{12} \mathrm{C}^{6+}(290 \mathrm{MeV} / \mathrm{u}),{ }^{20} \mathrm{Ne}^{10+}(400 \mathrm{MeV} / \mathrm{u}),{ }^{28} \mathrm{Si}^{14+}(490 \mathrm{MeV} / \mathrm{u})$, ${ }^{40} \mathrm{Ar}^{18+}(500 \mathrm{MeV} / \mathrm{u})$, and ${ }^{56} \mathrm{Fe}^{26+}(500 \mathrm{MeV} / \mathrm{u})$ for the irradiation experiments. The samples were exposed to the ion beams in the plateau region and the calculated dose-averaged LETs (hear after we simply use LET as dose-averaged LET) were as follows: $\mathrm{C}=13 \mathrm{keV} / \mu \mathrm{m}, \mathrm{Ne}=30 \mathrm{keV} / \mu \mathrm{m}, \mathrm{Si}=54 \mathrm{keV} / \mu \mathrm{m}, \mathrm{Ar}=89 \mathrm{keV} /$ $\mu \mathrm{m}$, and $\mathrm{Fe}=185 \mathrm{keV} / \mu \mathrm{m}$. Irradiation was performed in $10 \mathrm{~cm}$ diameter uniform-field beam. Polycarbonate containers (ca. $7 \mathrm{~cm} \times 7 \mathrm{~cm} \times 10 \mathrm{~cm}$ ) containing cultured gentians or apple tree twigs were placed on the target stage of the ion beam irradiation apparatus and the samples were exposed at a range of irradiation doses. Neutron irradiation experiments were conducted using the NASBEE facility at the NIRS with $2 \mathrm{MeV}$ monochromatic beam. The details of this system have been described previously (Suda et al. 2009).

\section{Cultivation of apple trees}

After irradiation, apple twigs were grafted onto JM1 clonal rootstocks through wedge grafts, and then the grafted

\section{Exposure to ion beam irradiation}
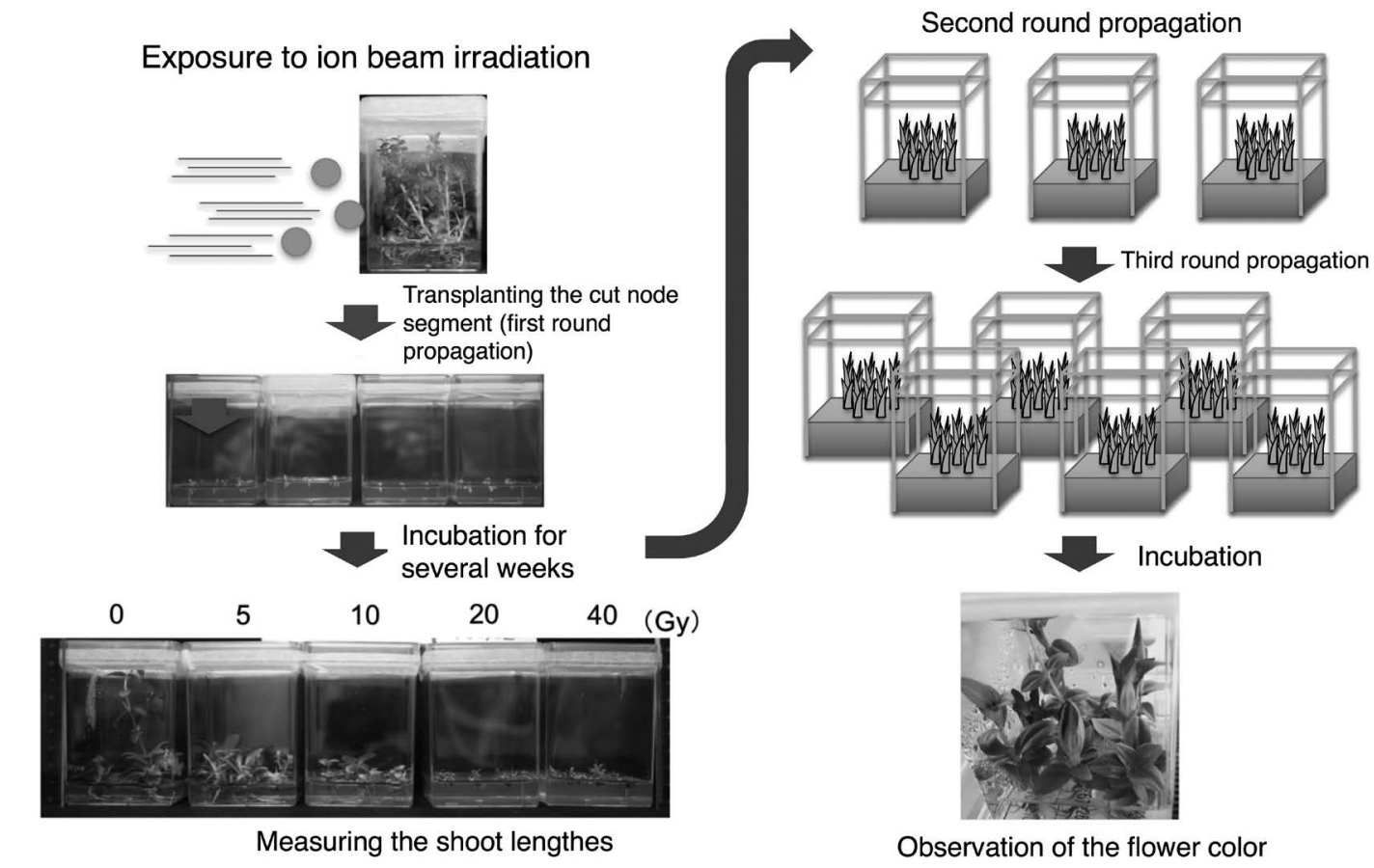

Observation of the flower color

Figure 1. Schematic procedure of heavy ion beam irradiation and evaluation of biological effects on Japanese gentian. Cultured Japanese gentians in a tissue culture box were placed on the target in the ion beam irradiation room. Nodal segments cut from irradiated samples were transplanted into new tissue culture boxes and shoot length was measured after further culturing for several weeks. After that, the plants were grown until they were ready to transplant, and then nodal segments were cut from the plants and transplanted into new boxes to increase plant numbers. The plant number was increased sufficiently by another round of propagation. The flower color of flowering plants in vitro was observed after three rounds of subculturing in total. 
Table 1. The schedule of the ion beam irradiation experiments performed in present study.

\begin{tabular}{|c|c|c|c|c|c|c|c|}
\hline \multirow[b]{2}{*}{ Ion species } & \multirow{2}{*}{$\begin{array}{c}\text { Calculated } \\
\text { LET } \\
(\mathrm{keV} / \mu \mathrm{m})\end{array}$} & \multicolumn{3}{|c|}{ Japanese gentian } & \multicolumn{3}{|c|}{ Apple trees } \\
\hline & & Radiation date & $\begin{array}{l}\text { Plant transferring } \\
\text { date }\end{array}$ & Measuring date & Radiation date & $\begin{array}{l}\text { Grafting and } \\
\text { planting date }\end{array}$ & Measuring date \\
\hline${ }^{12} \mathrm{C}^{6+}$ & 13 & May 29, 2015 & Jun 18, 2015 & Sep 11, 2015 & May 29, 2015 & Jun 1,2015 & Sep 11, 2015 \\
\hline${ }^{20} \mathrm{Ne}^{10+}$ & 30 & Oct 26,2013 & Nov 12, 2013 & Dec 16, 2013 & May 24, 2014 & May 26, 2014 & Aug 27, 2014 \\
\hline${ }^{28} \mathrm{Si}^{14+}$ & 54 & Apr 19, 2016 & May 27, 2016 & Oct 5, 2016 & Apr 19, 2016 & Apr 27, 2016 & Oct 5,2016 \\
\hline${ }^{40} \mathrm{Ar}^{18+}$ & 89 & Apr 16, 2014 & Apr 25, 2014 & Jun 12, 2014 & Apr 16, 2014 & Apr 18, 2014 & Aug 27, 2014 \\
\hline${ }^{56} \mathrm{Fe}^{26+}$ & 185 & May 12, 2016 & May 19, 2016 & Aug 2, 2016 & May 12, 2016 & May 18, 2016 & Aug 27, 2016 \\
\hline Neutron & - & Dec 17, 2015 & Dec 25,2015 & Feb 16, 2016 & May 25, 2016 & May 31, 2016 & Oct 5,2016 \\
\hline
\end{tabular}

rootstocks were planted in a field at the Iwate Agricultural Research Center $\left(39^{\circ} 21^{\prime} \mathrm{N}, 141^{\circ} 6^{\prime} \mathrm{E}\right)$. Four budwood twigs were grafted and grown for each irradiation condition. The irradiation and grafting date for each ion beam irradiation treatment are summarized in Table 1 . The lengths of newly extended branches were measured after sufficient growth of the apple trees (measuring dates are shown in Table 1). The biological effects were evaluated by summing up the lengths of new growth on the branches. Statistical analyses (TukeyKramer and Dunnett's test) were performed as mentioned above.

\section{Gene transcript analysis by RT-PCR}

To analyze gene transcript levels in gentian lines with changed flower color, RNAs were extracted and reverse transcription analyses were conducted as described in our previous report (Sasaki et al. 2015). The PCRs were performed using PrimeStar GXL DNA polymerase (Takara Bio. Shiga, Japan) with the following thermal program: $98^{\circ} \mathrm{C}, 10 \mathrm{~s} ; 62^{\circ} \mathrm{C}, 15 \mathrm{~s} ; 68^{\circ} \mathrm{C}, 2 \mathrm{~min}$ (25 cycles for $F 3^{\prime} 5^{\prime} H$ and 35 cycles for DFR). The primer sets were as follows: for $F 3^{\prime} 5^{\prime} H$, GsF3' $5^{\prime}$ Hatg: $5^{\prime}$-ATG TCA CCC ATT TAC ACC ACC CTC A-3' and GsF3'5'Hstp: 5' -TTA AGG AGC ATA AAC ATG AAG AGG A-3'; for DFR, sense: 5'-ATG GAA GGA GGG ATT TTA TCA AAT G-3' and antisense: $5^{\prime}$-CTA GTC TAG TGA ATC TTG AAT CAG T-3'. Un-irradiated original cultures were used as the controls.

\section{Genomic PCR analysis}

For the genomic analyses of gentian lines showing changed flower color, genomic DNA was extracted from the petals using a DNeasy Plant Mini Kit (Qiagen, Valencia, CA, USA) following the manufacturer's protocol. Genomic PCR was performed using PrimeStar GXL DNA polymerase and the primer set GsF3'5'Hatg and GsF3'5'Hstp with the following thermal program: 35 cycles of $98^{\circ} \mathrm{C}, 10 \mathrm{~s} ; 62^{\circ} \mathrm{C}, 15 \mathrm{~s}$; and $68^{\circ} \mathrm{C}$, $2 \mathrm{~min}$. Un-irradiated original cultures were used as the controls.

\section{Results and discussion}

\section{Biological effects of heavy ion beam irradiation on Japanese gentian}

The LET is an important factor in the biological effects of heavy ion beam irradiation. Heavy ion beams have the highest LET near the Bragg peak and remarkable
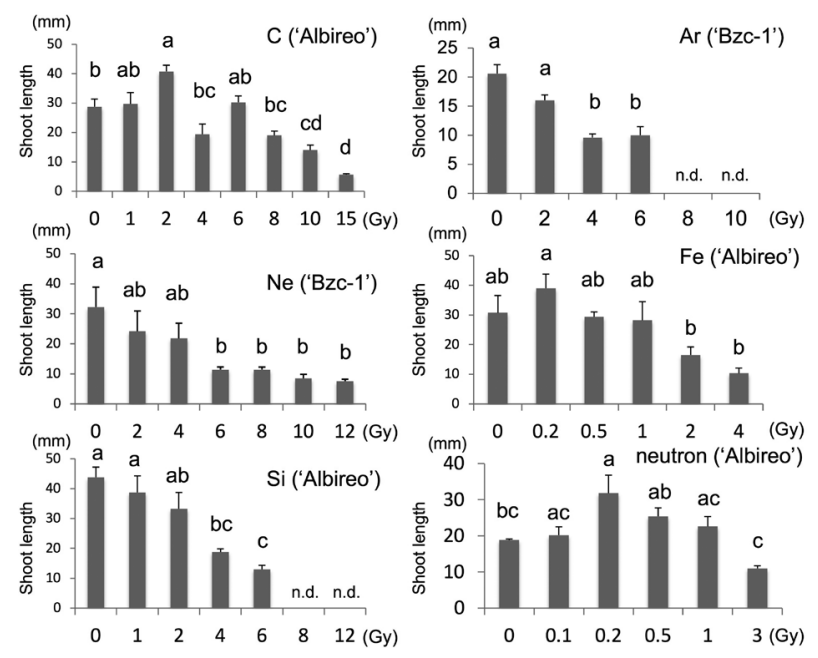

Figure 2. Biological effects of ion beam irradiation on cultured Japanese gentian. n.d., not determined because of insufficient sample size. Bars indicate standard error $(n=4-6)$. Different letters indicate significant difference between groups (Tukey-Kramer test, $p<0.05$ ).

changes in LET near the peak. Consequently, there are large changes in LET within a small micron range, making it difficult to estimate the precise LET irradiated onto the plant materials. The irradiation device at the HIMAC facility generates high energy ion beams with a large plateau region, so the fluctuation of LET through the plant materials was estimated to be less than $10 \%$. This resulted in highly reproducible irradiation treatments. To assess the biological effects of ion beams on Japanese gentian, we used gentian shoots grown in a culture box (nine plants per box). At first we tried to use the same cultivar in all experiments. However, we could not obtain sufficient shoots from the same cultivar for all irradiation experiments. Therefore, we used different cultivar/lines that grew appropriately for each irradiation experiment. Internode segments were cut from irradiated cultured gentian plants and transferred to new media. The experimental scheme for cultured gentian is shown in Figure 1. The lengths of elongated lateral buds were measured after 3-4 weeks (exact times are shown in Table 1). Growth was repressed by $\mathrm{C}$ ion beams at irradiation doses of $\geq 8 \mathrm{~Gy}$ and strongly inhibited by doses at $15 \mathrm{~Gy}$ (Figure 2), consistent with the results of a previous study on $\mathrm{C}$ ion beam irradiation of 
chrysanthemum lateral buds (Yamaguchi et al. 2009b). The plants irradiated with $\mathrm{C}$ ion beams at $2 \mathrm{~Gy}$ grew faster than un-irradiated plants (0 Gy). When $\mathrm{Ne}$ ion beams were used, growth was decreased less than half of that of un-irradiated plants at doses of $\geq 6 \mathrm{~Gy}$. Irradiation with $\mathrm{Si}$ and $\mathrm{Ar}$ ion beams at $4 \mathrm{~Gy}$ inhibited growth by approximately $50 \%$ compared with that of un-irradiated plants, and plant growth was strongly repressed by both $\mathrm{Si}$ and $\mathrm{Ar}$ ion beam irradiation at $\geq 8 \mathrm{~Gy}$. The growth of gentians was inhibited by $\mathrm{Fe}$ ion beam irradiation at $2 \mathrm{~Gy}$ and strongly inhibited by it at $4 \mathrm{~Gy}$. A previous study showed that $\geq 250$ Gy doses of ion beams (LET $=60 \mathrm{keV}$ / $\mu \mathrm{m})$ were required to decrease flowering rate on Arabidopsis seeds (Kazama et al. 2011). Another report showed that much higher irradiation doses (ca. 20 Gy) were required to affect the survival of rice seeds, even using $\mathrm{C}$ ion beams that had much higher LET $(107 \mathrm{keV} /$ $\mu \mathrm{m})$ (Yamaguchi et al. 2009a) than that of the beams used in our study. The fact that smaller irradiation doses had biological effects on Japanese gentian shoots and on chrysanthemum lateral buds (Yamaguchi et al. 2009b) implies that vegetative tissues are more sensitive to ion beams than are seeds.

The growth of cultured gentian was slightly affected by neutron irradiation at $3 \mathrm{~Gy}$, but not at $\leq 1 \mathrm{~Gy}$. Therefore, much higher doses would be needed to evaluate the biological effects of neutron irradiation.

\section{Flower color changes resulting from heavy ion beam irradiation}

We used the cultivar 'Aokorin' and the breeding line 'Bzc-1' to estimate the mutagenesis rate, because these lines can be vegetatively propagated and readily in vitro bloom. To evaluate the mutagenesis rate, we focused on a flower color change from blue to pink, because this trait is more easily observable than other traits such as flower color intensity, plant height, leaf shape, and flowering time. In fact, we could observe some phenotypes such as stunted growth, split petals, faint or bicolor flowers. It was, however, difficult to evaluate these traits exactly because some in vitro bloomed flowers showed similar phonotypes even if they were not subjected to ion beam irradiation. After three rounds of subculturing the internodes cut from irradiated Japanese gentian, individual plantlets were numbered and maintained in vitro until flowering. In total, 959 'Bzc-1' plantlets irradiated with $\mathrm{C}$ ions were obtained, and 221 of them flowered (Table 2). A flower color change from blue to pink was observed in four lines from the 10-Gy irradiation treatment. We obtained 1,014 plantlets of 'Aokorin' after irradiation with $\mathrm{Ne}$ ion beams, and 530 of them flowered. Because growth was suppressed by high irradiation doses, fewer plantlets were obtained for the 7-Gy and 8-Gy Ne irradiation treatments. Flower color shifts were observed in one line in the 5-Gy Ne irradiation treatment and two lines in the 7-Gy Ne irradiation treatment. The number of plantlets obtained in the $\geq 15-\mathrm{Gy} C$ irradiation and $10-\mathrm{Gy} \mathrm{Ne}$ irradiation treatments was insufficient for analysis, because these treatments were lethal or strongly suppressed growth. Although whether all the mutation events occurred independently or some originated from the same event remained unknown, the apparent total mutation ratio (frequency of pink-flowered lines) was $1.8 \%$ (C irradiation treatments) and $0.56 \%$ (Ne irradiation treatments). However, it is noteworthy that $7 \%$ and $8.3 \%$ of plants showed the same type of mutation in the 10Gy C and 7-Gy Ne ion beam irradiation treatments, respectively. Out of 59 plants that flowered after the 6-Gy Ne irradiation treatment, no mutant was obtained, implying that the mutation rate was lower than that obtained with 7-Gy Ne irradiation. Therefore, it was estimated that $7 \mathrm{~Gy}$ of $\mathrm{Ne}$ and $10 \mathrm{~Gy}$ of $\mathrm{C}$ had the highest mutation rate among tested doses. The Ne ion beam had greater LET than that of the C ion beam, and so it caused mutations at lower doses. Interestingly, both of those irradiation doses repressed gentian growth in vitro to around $50 \%$ of that of non-irradiated plants (Figure 2). Thus, the irradiation dose that represses plant growth by half may be a good indicator to select a suitable dose of other ion beams for mutagenesis, although further research is required to confirm this. Furthermore, for $\mathrm{C}$ and $\mathrm{Ne}$ ion beam irradiation, a high rate of mutation could be induced within a narrow range of doses (within a few Gy irradiation doses). The combination of ion beams with variable LET and a suitable irradiation dose might be an important factor for ion beam mutagenesis. Therefore, the irradiation doses should be optimized for each plant material for efficient mutagenesis. The effects of ion beam irradiation on various aspects of plant growth (such as flowering) should also be considered when using this system to generate mutants. The use of appropriate irradiation doses will ensure a balance between plant growth and mutation frequency.

Table 2. Propagated plantlet numbers and mutation frequency stimulated by ion beam irradiation in in vitro cultured Japanese gentian.

\begin{tabular}{|c|c|c|c|c|c|c|c|c|c|c|c|c|c|c|}
\hline \multirow{2}{*}{ Irradiation dose } & \multicolumn{7}{|c|}{$\mathrm{C}\left(\right.$ ('Bzc-1') $^{\prime}$} & \multicolumn{7}{|c|}{$\mathrm{Ne}$ ('Aokorin') } \\
\hline & $1 \mathrm{~Gy}$ & $2 \mathrm{~Gy}$ & $4 \mathrm{~Gy}$ & $6 \mathrm{~Gy}$ & $8 \mathrm{~Gy}$ & $10 \mathrm{~Gy}$ & Total & $3 \mathrm{~Gy}$ & $4 \mathrm{~Gy}$ & $5 \mathrm{~Gy}$ & $6 \mathrm{~Gy}$ & $7 \mathrm{~Gy}$ & $8 \mathrm{~Gy}$ & Total \\
\hline Plantlet number & 183 & 132 & 138 & 204 & 127 & 175 & 959 & 253 & 188 & 308 & 154 & 64 & 47 & 1014 \\
\hline Flowering number & 45 & 32 & 34 & 27 & 26 & 57 & 221 & 162 & 107 & 161 & 59 & 24 & 17 & 530 \\
\hline Pink mutant number & 0 & 0 & 0 & 0 & 0 & $4(7 \%)$ & $4(1.8 \%)$ & 0 & 0 & $1(0.6 \%)$ & 0 & $2(8.3 \%)$ & 0 & $3(0.56 \%)$ \\
\hline
\end{tabular}


a)

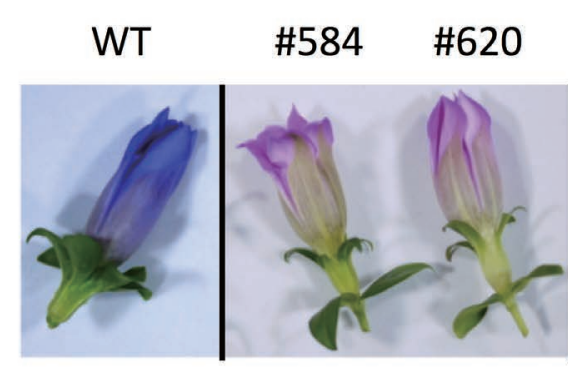

b)
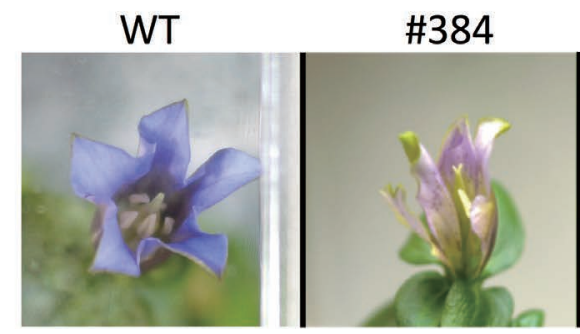

\#384

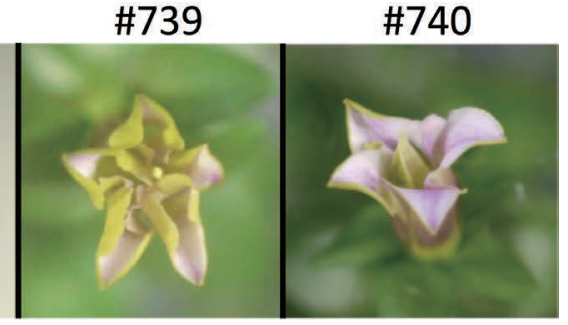

Figure 3. Pink-flowered mutant gentian lines obtained by ion beam irradiation. Pink-flowered 'Bzc-1' line obtained by C ion beam irradiation (a) and pink-flowered 'Aokorin' obtained by Ne ion beam irradiation (b).

\section{Analyses of gene expression in gentian flower- color mutants}

The blue flower color of gentian is attributable to the delphinidin-type anthocyanin gentiodelphin (Goto et al. 1982), and the pink flower color to the cyanidintype anthocyanin gentiocyanin. The pink color shift was found to be caused by the disruption of the flavonoid $3^{\prime}, 5^{\prime}$-hydroxylase $\left(F^{\prime} 5^{\prime} H\right)$ gene in several gentian lines and cultivars (Nakatsuka et al. 2006; Nishihara et al. 2011). Therefore, we analyzed the transcript levels of $\mathrm{F}^{\prime} 5^{\prime} \mathrm{H}$ in the mutant lines (Figure 3 ) by reversetranscription PCR. Transcripts with the expected length (ca. $1.5 \mathrm{kbp}$ ) were amplified from lines with blue flowers (wild-type flower color) (Figure 4a). However, $F^{\prime} 5^{\prime} H$ transcripts were not detectable in the mutant lines, indicating that a lack of $F 3^{\prime} 5^{\prime} H$ gene expression was responsible for the pink flower color (Figure 4a). The transcript levels of the control gene, DFR, were the same in all the samples (Figure 4a). This result implied that both $\mathrm{C}$ and $\mathrm{Ne}$ ion beams caused large deletions of genomic regions rather than substitutions, insertions, or deletions of only one or a few nucleotides. In previous studies, ion bean irradiation caused the deletion of a large genomic region in carnation (Okamura et al. 2013) and several kinds of mutations such as single nucleotide substitutions, small and large insertion and deletions, and genomic rearrangements in Arabidopsis (Kazama et al. 2011, 2013). Ion beams can also induce large genomic alterations such as chromosomal rearrangements (Sakamoto et al. 2017).

\section{Genomic PCR analysis of $F 3^{\prime} 5^{\prime} H$ gene in flower- color mutants}

First, we analyzed the $F 3^{\prime} 5^{\prime} H$ genotype of 'Aokorin' and 'Bzc-1.' Amplicons of two different lengths were detected a) RT-PCR

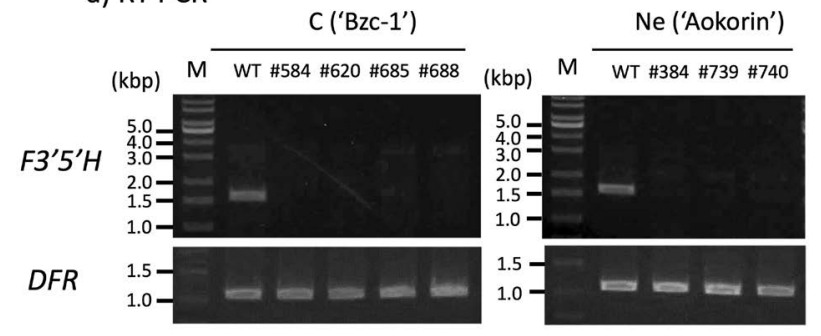

b) genomic PCR

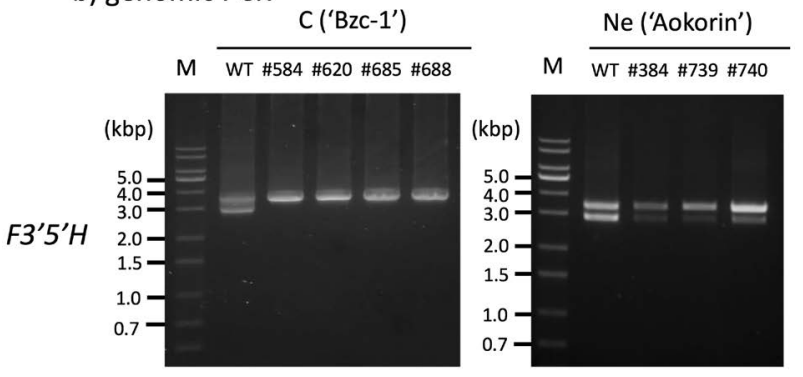

Figure 4. Genetic analyses of pink-flowered mutant lines. Transcript levels of $F 3^{\prime} 5^{\prime} H$ gene were analyzed by RT-PCR (a). $F 3^{\prime} 5^{\prime} H$ amplicons with the expected length were detected from lines with blue (wildtype) flowers, but not from pink-flowered mutant lines. DFR served as the experimental control. Genomic PCR analysis of DNAs extracted from petals of mutant lines (b). Two bands were amplified from blueflowered (wild-type) lines. Longer band corresponds to defective transposon-inserted $f 3^{\prime} 5^{\prime} h$ and shorter one corresponds to functional intact $F 3^{\prime} 5^{\prime} H$. Only longer bands were detected in all mutant lines obtained by $\mathrm{C}$ ion beam irradiation; both bands were detected in lines obtained by $\mathrm{Ne}$ ion beam irradiation.

by genomic PCR using the primer set designed to amplify the open reading frame (Figure 4b). Two clear bands were observed in wild-type lanes of 'Aokorin' and 'Bzc-1' (Figure 4b, both wild-type lanes). Subsequent DNA sequencing analyses revealed that 'Aokorin' was heterozygous for $F 3^{\prime} 5^{\prime} H$, with the GsTRIM1 transposable 
element integrated into one $F 3^{\prime} 5^{\prime} H$ allele $\left(f 3^{\prime} 5^{\prime} h 1^{\text {GsTRIMI }}\right.$ ) as reported for the pink cultivar 'Momokorin' (Nakatsuka et al. 2006). The longer band in 'Aokorin' wild-type lane corresponded to this $f 3^{\prime} 5^{\prime} h 1^{\text {GsTRIMI }}$ genomic region (the amplicon size was estimated as ca. $3.4 \mathrm{kbp}$ ). 'Bzc-1' was also heterozygous for $F^{\prime} 5^{\prime} H$ with the GtMITE1 transposable element inserted into one $F 3^{\prime} 5^{\prime} H$ allele $\left(f 3^{\prime} 5^{\prime} h 1^{\text {GtMITEI }}\right)$ as reported for pink cultivar 'Maerchen Ashiro' (Nishihara et al. 2011) (data not shown). The longer band in 'Bzc-1' wild-type lane corresponded to this $f 3^{\prime} 5^{\prime} h 1^{G T M I T E 1}$ genomic region (the amplicon size was estimated as ca. $3.4 \mathrm{kbp}$ ). In the genomic PCR analysis, only the band corresponding to the deficient GTMITE1inserted $f 3^{\prime} 5^{\prime} h 1^{G T M I T E 1}$ allele was detected in all mutant lines obtained by $\mathrm{C}$ ion beam irradiation in 'Bzc-1' (Figure $4 \mathrm{~b}$, left panel). There are several possible types of mutations that may have occurred in the $F 3^{\prime} 5^{\prime} H$ gene, including long-range deletion, genomic rearrangement, or a single nucleotide substitution or insertion/deletion of a few nucleotides at the primer site. The genomic PCR analysis detected both amplicons of the intact and deficient $f 3^{\prime} 5^{\prime} h 1^{\text {GSTRIM1 }}$ alleles in the mutant lines of 'Aokorin' obtained by Ne ion beam irradiation. However, the lower band corresponding to the intact $F 3^{\prime} 5^{\prime} H$ allele was weak. Considering this result and the fact that $F 3^{\prime} 5^{\prime} H$ transcripts were not detected in any of the lines described above, these Ne ion-induced 'Aokorin' mutant lines might have been chimeric plants in which only the petal epidermal layer lacked the intact $F 3^{\prime} 5^{\prime} H$. Further analyses by genomic PCR using pollen or progeny are required to confirm the nature of the mutation. We note that chimerization by ion beam irradiation has been reported previously for chrysanthemum (Matsumura et al. 2010; Yamaguchi et al. 2009b). It is also unclear whether all the mutation events occurred independently or whether some originated from the same event. Further analyses such as whole genome sequencing are necessary to gain insights into the genomic changes in these gentian mutants.

\section{Effect of irradiation on apple trees}

To assess the effects of ion beam irradiation on the growth of apple, we exposed apple tree twigs to the five ion beams at a range of doses. After the irradiated twigs were grafted onto rootstocks, the growth of newly extended branches was evaluated. The average amount of new branch growth differed even among controls, probably because of differences in the time after grafting and/or the climatic conditions in the field. Apple tree twigs were irradiated with $\mathrm{C}$ ion beams at $4,10,15,20,25,30$, and $50 \mathrm{~Gy}$. The growth of the newly elongated branches was weakly inhibited by $\mathrm{C}$ irradiation at doses of $\geq 4 \mathrm{~Gy}$, and strongly inhibited by doses of $\geq 25 \mathrm{~Gy}$. Very little growth was observed after $\mathrm{C}$ ion beam irradiation at $50 \mathrm{~Gy}$ (data not shown). The
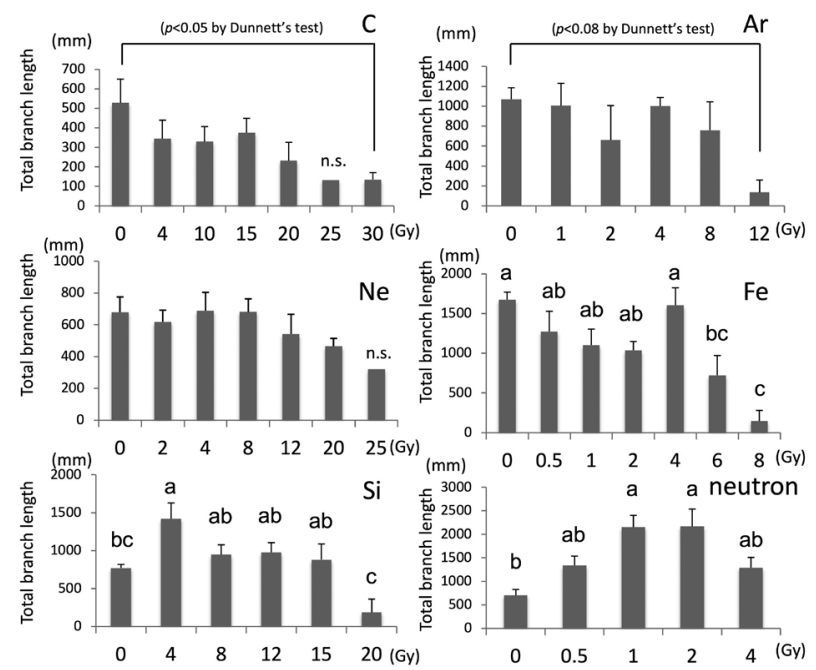

Figure 5. Biological effects of ion beam irradiation on apple trees. Sum of length of newly extended branches after grafting was calculated $(n=4)$. n.s., Average of two plants is shown, because other two plants showed growth inhibition. Bars indicate standard errors. Different letters indicate significant difference between groups (Tukey-Kramer test, $p<0.05)$.

$\mathrm{Ne}$ ion beam irradiation was applied at doses of 2, 4, 8, 12,20 , and $25 \mathrm{~Gy}$. Weak growth inhibition was observed after irradiation at $20 \mathrm{~Gy}$, but no effects were detected at doses of $\leq 12 \mathrm{~Gy}$. Two out of four samples in the $25-\mathrm{Gy}$ treatment showed growth inhibition, but it was unclear whether this was caused by the ion beam irradiation. The Si ion beam irradiation treatment at 20 Gy strongly inhibited growth, but barely affected growth at doses of $\leq 15 \mathrm{~Gy}$. The Ar ion beam irradiation treatment was applied at doses of 1, 2, 4, 8, and 12 Gy. Growth was weakly inhibited by Ar irradiation at $8 \mathrm{~Gy}$ but strongly inhibited by it at $12 \mathrm{~Gy}$. The $\mathrm{Fe}$ ion beam irradiation treatment was applied at doses of $0.5,1,2,4,6$, and $8 \mathrm{~Gy}$. The growth inhibition rates gradually increased as the irradiation dose increased to $6 \mathrm{~Gy}$, and growth was strongly repressed by 8 -Gy irradiation.

Our results suggested that the biological effects on apple might be classified into two types: growth inhibition, which showed a gradual increase in severity as the ion beam irradiation dose increased (as observed in the $\mathrm{C}$ and $\mathrm{Ne}$ ion beam irradiation treatments); and severe biological effects that occurred over a threshold dose (as observed in the $\mathrm{Si}, \mathrm{Ar}$, and $\mathrm{Fe}$ ion beam treatments). It is uncertain whether this phenomenon is due to the LET value of each ion species or the character of each atom. These results indicated that the irradiation dose should be carefully selected when heavier ion species such as $\mathrm{Si}, \mathrm{Ar}$ and $\mathrm{Fe}$ are used, because the threshold ranges might be relatively narrow.

We used Japanese gentian and apple, two plant materials belonging to very different plant orders. Gentian belongs to the Gentianales and apple to the Rosales. Gentian is an herbaceous plant and apple is a 
woody plant. Furthermore, the genome sizes of gentian and apple were estimated to be ca. $5 \mathrm{Gbp}$ and $600 \mathrm{Mbp}$, respectively (Mishiba et al. 2009; Velano et al. 2010). Despite those substantial differences, the sensitivities of both plants to ion beam irradiation treatment were not so different compared with the sensitivity of seeds. For several plant species, high doses of irradiation must be supplied to seeds to repress germination and growth. This implies that the sensitivity to ion beams mainly depends on the target material, rather than the plant species. For all ion species, the irradiation doses that inhibited growth of apple trees were higher than those of Japanese gentian. It may depend on the difference of irradiated target materials between gentian shoots and apple twigs. However, there is another possibility that it might be caused by different genome size between these two plant species. It is reported that the different sensitivity to DNA damage of plants impacted by X-ray depends on their genome size (Einset and Collins 2017). They proposed a 10 -fold increase genome size increases about 2-fold sensitivity to DNA damage. Since Japanese gentian's genome size is estimated as ca. $5 \mathrm{Gbp}$ that is ca. 10-fold lower than apple genome size, it is likely that apple tree showed less sensitivity to ion beam irradiation than Japanese gentian.

Among all the treatments, neutron irradiation across the range of 0.5 to $4 \mathrm{~Gy}$ and Si ion beam irradiation resulted in better growth of apple tree branches. For Japanese gentian, the best growth was in the low-level C ion beam irradiation treatments. This phenomenon may reflect a hormesic effect; that is, a growth-promoting effect of small doses of ionizing radiation (Qi et al. 2015).

In conclusion, we conducted experiments to develop methods of generating radiation mutants in perennial Japanese gentian and apple. The ion beam and neutron irradiation treatments of gentian vegetative tissues led to growth inhibition with relatively low-dose exposures ( $\leq 10 \mathrm{~Gy}$ ). In Japanese gentian, several mutant lines exhibiting the same phenotype (pink flower color) were obtained by $\mathrm{C}$ and $\mathrm{Ne}$ ion beam irradiation. Genetic analyses suggested that some mutations had occurred in $F 3^{\prime} 5^{\prime} H$ gene by the ion beam irradiation treatment in those mutants. We also obtained basic data about irradiation of apple trees. These data will be useful for further research on ion beam mutagenesis of not only gentian and apple, but also other perennial plants.

\section{Acknowledgements}

This article is associated with The JSPCMB Award for Young Investigator to NS in 2016. The authors are grateful to the Editorin-Chief of Plant Biotechnology for the kind invitation to submit this article. The authors thank Ms. E. Chiba and K. Kurokawa for technical assistance with the experiments, and Dr. M. Okamura for useful guidance in the ion beam irradiation experiments. This research was supported by the Research Project with Heavy
Ions at NIRS-HIMAC. Neutron exposure was conducted at the shared facility of the National Institute of Radiological Sciences, the Radiological Science Research and Development Directorate of the National Institute for Quantum and Radiological Science and Technology, under the dedicated support of its staff. We thank Jennifer Smith, PhD, from Edanz Group (www.edanzediting.com/ ac) for editing a draft of this manuscript.

\section{References}

Al-Khayri JM, Jain SM, Johnson DV (2015) Advances in Plant Breeding Strategies: Breeding, Biotechnology and Molecular Tools. Springer International Publishing, Cham.

Charlesworth D (2006) Evolution of plant breeding systems. Curr Biol 16: R726-R735

Einset J, Collins AR (2017) Genome size and sensitivity to DNA damage by X-rays: Plant comets tell the story. Mutagenesis 33: $49-51$

El-Nashar YI, Asrar AA (2016) Phenotypic and biochemical profile changes in calendula (Calendula officinalis L.) plants treated with two chemical mutagenesis. Genet Mol Res 15: 1-14

Goto T, Kondo T, Tamura H, Imagawa H, Iino A, Takeda K (1982) Structure of gentiodelphin, an acylated anthocyanin isolated from Gentiana Makinoi, that is stable in dilute aqueous solution. Tetrahedron Lett 23: 3695-3698

Hase Y, Okamura M, Takeshita D, Narumi I, Tanaka A (2010) Efficient induction of flower-color mutants by ion beam irradiation in petunia seedlings treated with high sucrose concentration. Plant Biotechnol 27: 99-103

Igarashi M, Hatsuyama Y, Harada T, Fukasawa-Akada T (2016) Biotechnology and apple breeding in Japan. Breed Sci 66: 18-33

Jankowicz-Cieslak J, Tai Th-H, Kumlehn J, Till B-J (2017) Biotechnologies for Plant Mutation Breeding. Springer International Publishing, Cham.

Kakizaki Y, Nakatsuka T, Kawamura H, Abe J, Abe Y, Yamamura S, Nishihara M (2009) Development of codominant DNA marker distinguishing pink from blue flowers in Gentiana scabra. Ikushugaku Kenkyu 11: 9-14 (in Japanese with English abstract)

Kazama Y, Hirano T, Nishihara K, Ohbu S, Shirakawa Y, Abe T (2013) Effect of high-LET Fe-ion beam irradiation on mutation induction in Arabidopsis thaliana. Genes Genet Syst 88: 189-197

Kazama Y, Hirano T, Saito H, Liu Y, Ohbu S, Hayashi Y, Abe $\mathrm{T}$ (2011) Characterization of highly efficient heavy-ion mutagenesis in Arabidopsis thaliana. BMC Plant Biol 11: 161

Kazama Y, Saito H, Miyagai M, Takehisa H, Ichida H, Miyazawa Y, Mishiba KI, Kanaya T, Suzuki K, Bae CH, et al. (2008) Effect of heavy ion-beam irradiation on plant growth and mutation induction in Nicotiana tabacum. Plant Biotechnol 25: 105-111

Kondo E, Nakayama M, Kameari N, Tanikawa N, Morita Y, Akita Y, Hase Y, Tanaka A, Ishizaka H (2009) Red-purple flower due to delphinidin 3,5-diglucoside, a novel pigment for Cyclamen spp., generated by ion-beam irradiation. Plant Biotechnol 26: 565-569

Lee SY, Cheong JI, Kim ST (2003) Production of doubled haploids through anther culture of M1rice plants derived from mutagenized fertilized egg cells. Plant Cell Rep 22: 218-223

Matsumura A, Nomizu T, Furutani N, Hayashi K, Minamiyama Y, Hase Y (2010) Ray florets color and shape mutants induced by $12 \mathrm{C} 5+$ ion beam irradiation in chrysanthemum. Sci Hortic (Amsterdam) 123: 558-561

Matsuo T, Yamaguchi H, Ando A (1958) A comparison of biological effects between thermal neutrons and X-rays on rice seeds. Japanese J Breed 8: 37-45 
Mishiba K, Yamane K, Nakatsuka T, Nakano Y, Yamamura S, Abe J, Kawamura H, Takahata Y, Nishihara M (2009) Genetic relationships in the genus Gentiana based on chloroplast DNA sequence data and nuclear DNA content. Breed Sci 59: 119-127

Nakatsuka T, Nishihara M, Mishiba K, Hirano H, Yamamura S (2006) Two different transposable elements inserted in flavonoid $3^{\prime}, 5^{\prime}$-hydroxylase gene contribute to pink flower coloration in Gentiana scabra. Mol Genet Genomics 275: 231-241

Nakatsuka T, Nishihara M, Mishiba K, Yamamura S (2005) Temporal expression of flavonoid biosynthesis-related genes regulates flower pigmentation in gentian plants. Plant Sci 168: 1309-1318

Nakatsuka T, Saito M, Yamada E, Fujita K, Kakizaki Y, Nishihara M (2012) Isolation and characterization of GtMYBP3 and GtMYBP4, orthologues of R2R3-MYB transcription factors that regulate early flavonoid biosynthesis, in gentian flowers. $J$ Exp Bot 63: 6505-6517

Nakatsuka T, Saito M, Yamada Y, Fujita K, Yamagishi N, Yoshikawa N, Nishihara M (2015) Isolation and characterization of the C-class MADS-box gene involved in the formation of double flowers in Japanese gentian. BMC Plant Biol 15: 182

Nishihara M, Hikage T, Yamada E, Nakatsuka T (2011) A singlebase substitution suppresses flower color mutation caused by a novel miniature inverted-repeat transposable element in gentian. Mol Genet Genomics 286: 371-382

Nishihara M, Tasaki K, Sasaki N, Takahashi H (2018) Development of basic technologies for improvement of breeding and cultivation of Japanese gentian. Breed Sci 68: 14-24

Okamura M, Nakayama M, Umemoto N, Cano EA, Hase Y, Nishizaki Y, Sasaki N, Ozeki Y (2013) Crossbreeding of a metallic color carnation and diversification of the peculiar coloration by ion-beam irradiation. Euphytica 191: 45-56

Okamura M, Yasuno N, Ohtsuka M, Tanaka A, Shikazono N, Hase Y (2003) Wide variety of flower-color and -shape mutants regenerated from leaf cultures irradiated with ion beams. $\mathrm{Nucl}$ Instruments Methods Phys Res Sect B Beam Interact with Mater Atoms 206: 574-578

Qi W, Zhang L, Feng W, Xu H, Wang L, Jiao Z (2015) ROS and ABA signaling are involved in the growth stimulation induced by low-dose gamma irradiation in Arabidopsis seedling. Appl Biochem Biotechnol 175: 1490-1506

Ryuto H, Fukunishi N, Hayashi Y, Ichida H, Abe T, Kase M, Yano Y (2008) Heavy-ion beam irradiation facility for biological samples in RIKEN. Plant Biotechnol 25: 119-122

Sakamoto AN, Lan VTT, Fujimoto S, Matsunaga S, Tanaka A (2017) An ion beam-induced Arabidopsis mutant with marked chromosomal rearrangement. J Radiat Res (Tokyo) 15: 1-10

Sasaki N, Nishizaki Y, Yamada E, Tatsuzawa F, Nakatsuka T, Takahaashi H, Nishihara M (2015) Identification of the glucosyltransferase that mediates direct flavone $C$-glucosylation in Gentiana triflora. FEBS Lett 589: 182-187

Shikazono N, Tanaka A, Kitayama S, Watanabe H, Tano S (2002) LET dependence of lethality in Arabidopsis thaliana irradiated by heavy ions. Radiat Environ Biophys 41: 159-162

Suda M, Hagihara T, Suya N, Hamano T, Takada M, Konishi T, Maeda T, Ohmachi Y, Kakinuma S, Ariyoshi K, et al. (2009) Specifications of a neutron exposure accelerator system for biological effects experiments (NASBEE) in NIRS. Radiat Phys Chem 78: 1216-1219

Sugiyama M, Saito H, Ichida H, Hayashi Y, Ryuto H, Fukunishi N, Terakawa T, Abe T (2008) Biological effects of heavy-ion beam irradiation on cyclamen. Plant Biotechnol 25: 101-104

Tasaki K, Atsumi G, Nishihara M, Sekine KT (2016) Development of a Broad bean wilt virus 2-based expression vector for gentian. Sci Hortic (Amsterdam) 201: 279-286

Velasco R, Zharkikh A, Affourtit J, Dhingra A, Cestaro A, Kalyanaraman A, Fontana P, Bhatnagar SK, Troggio M, Pruss D, et al. (2010) The genome of the domesticated apple (Malus $\times$ domestica Borkh.). Nat Genet 42: 833-839

Yamaguchi H (2018) Mutation breeding of ornamental plants using ion beams. Breed Sci 68: 71-78

Yamaguchi H, Hase Y, Tanaka A, Shikazono N, Degi K, Shimizu A, Shimizu A, Morishita T (2009a) LET effects of ion beam irradiation on rice. Breed Sci 59: 169-177

Yamaguchi H, Shimizu A, Hase Y, Degi K, Tanaka A, Morishita T (2009b) Mutation induction with ion beam irradiation of lateral buds of chrysanthemum and analysis of chimeric structure of induced mutants. Euphytica 165: 97-103 